\title{
Doridicola similis (Copepoda: Poecilostomatoida: Rhynchomolgidae) Associated with Sepioteuthis sp. (Cephalopoda: Myopsida: Loliginidae), New to Japan
}

\author{
Fumitaka Kudoh ${ }^{1}$ and Kazuya Nagasawa ${ }^{1,2}$ \\ ${ }^{1}$ Graduate School of Biosphere Science, Hiroshima University, \\ 1-4-4 Kagamiyama, Higashi-Hiroshima, Hiroshima 739-8528, Japan \\ E-mail:ornatus@hiroshima-u.ac.jp \\ ${ }^{2}$ Corresponding author
}

(Received 29 January 2016; Accepted 18 May 2017)

\begin{abstract}
Female and male specimens of Doridicola similis Ho and Kim, 2001 (Copepoda: Poecilostomatoida: Rhynchomolgidae) from the gills of the loliginid squid Sepioteuthis sp. (called shiro-ika) (Cephalopoda: Myopsida: Loliginidae) in coastal Pacific waters of central Japan are described as a new country record. This collection represents the second record of D. similis and expands its distribution range from the Gulf of Thailand (type locality) northeast to the western North Pacific Ocean off central Japan.
\end{abstract}

Key Words: Doridicola similis, Sepioteuthis sp., new country record, symbiotic copepod, cephalopod.

\section{Introduction}

The symbiotic copepods of cephalopods are poorly known in Japan [see Nagasawa (1993) for the known parasites of Japanese cephalopods]. Originally, Lichomolgus sepiae Izawa, 1976 was described from the gills of Sepia esculenta Hoyle, 1885 (Sepiida: Sepiidae) in Tanabe Bay, Wakayama Prefecture, central Japan (Izawa 1976). Ho (1980) transferred this copepod species to Metaxymolgus Humes and Stock, 1972 (see also Ho 1983), but more recently, it has been placed in Doridicola Leydig, 1853 (Humes and Stock 1983; Izawa 1986; Ho and Kim 2001). Other than this, Avdeev (1982, 1986) described five species of tisbid copepods (Harpacticoida) taken mostly from deep-water octopods off the Pacific coasts of Honshu and Hokkaido, Japan: Cholidyella incisa Avdeev, 1982 (generic name initially misspelled as Cholydiella) from Graneledone sp. (Megaleledonidae); C. breviseta Avdeev, 1986 from Opisthoteuthis californiana Berry, 1949 (Opisthoteuthidae); C. nesisi Avdeev, 1986 from Muusoctopus profundorum (Robson, 1932) (as Benthoctopus profundorum) (Enteroctopodidae) and M. fuscus (Taki, 1964) (as B. fuscus); Brescianiana rotundus Avdeev, 1982 from Graneledone sp.; and Octopinella tenacis Avdeev, 1986 from B. profundorum (Enteroctopodidae), Octopus longispadiceus (Sasaki, 1917) (Octopodidae), and Octopus sp.

Here we report on recently collected female and male $D o$ ridicola similis Ho and Kim, 2001 from the gills of loliginid squids in coastal Pacific waters of central Japan. This copepod so far has been reported only from Thailand (Ho and Kim 2001). We thus report $D$. similis as a new country record and provide a morphological description of the specimens.

\section{Materials and Methods}

Two individual squids, which were later identified as Sepioteuthis sp. 2 (called shiro-ika, see Imai and Aoki 2012) based on molecular analysis (Satoshi Tomano, Graduate School of Biosphere Science, Hiroshima University personal communication), were collected by lure fishing in Owase Bay $\left(34^{\circ} 05^{\prime} 37.7^{\prime \prime} \mathrm{N}, 136^{\circ} 14^{\prime} 45.2^{\prime \prime} \mathrm{E}\right)$ off the coast of Hiki-Motoura, Kihoku, Mie Prefecture, Honshu, central Japan, on 21 July 2015. The dorsal mantle length (DML) of each squid was recorded, and the gills were removed from both specimens, and transported on ice to the laboratory at Hiroshima University, Higashi-Hiroshima, Hiroshima Prefecture, where copepods were carefully removed from the gills and fixed in $70 \%$ ethanol. Five females and 10 males of copepods were later soaked in lactophenol, dissected, and observed using the wooden slide method of Humes and Gooding (1964). Drawings were made with the aid of a drawing tube fitted on an Olympus BX51 compound microscope. Measurements are given as the range followed by the mean in parentheses. Morphological terminology follows mainly Humes and Boxshall (1996). Voucher specimens are deposited in the Crustacea collection of the National Museum of Nature and Science, Tsukuba, Ibaraki Prefecture, Japan (NSMT-Cr 25448 for four females and 25449 for four males).

\section{Doridicola similis Ho and Kim, 2001}

(Figs 1-3)

Doridicola similis Ho and Kim, 2001: 80-84, figs 1-3 (type locality: Gulf of Thailand). 


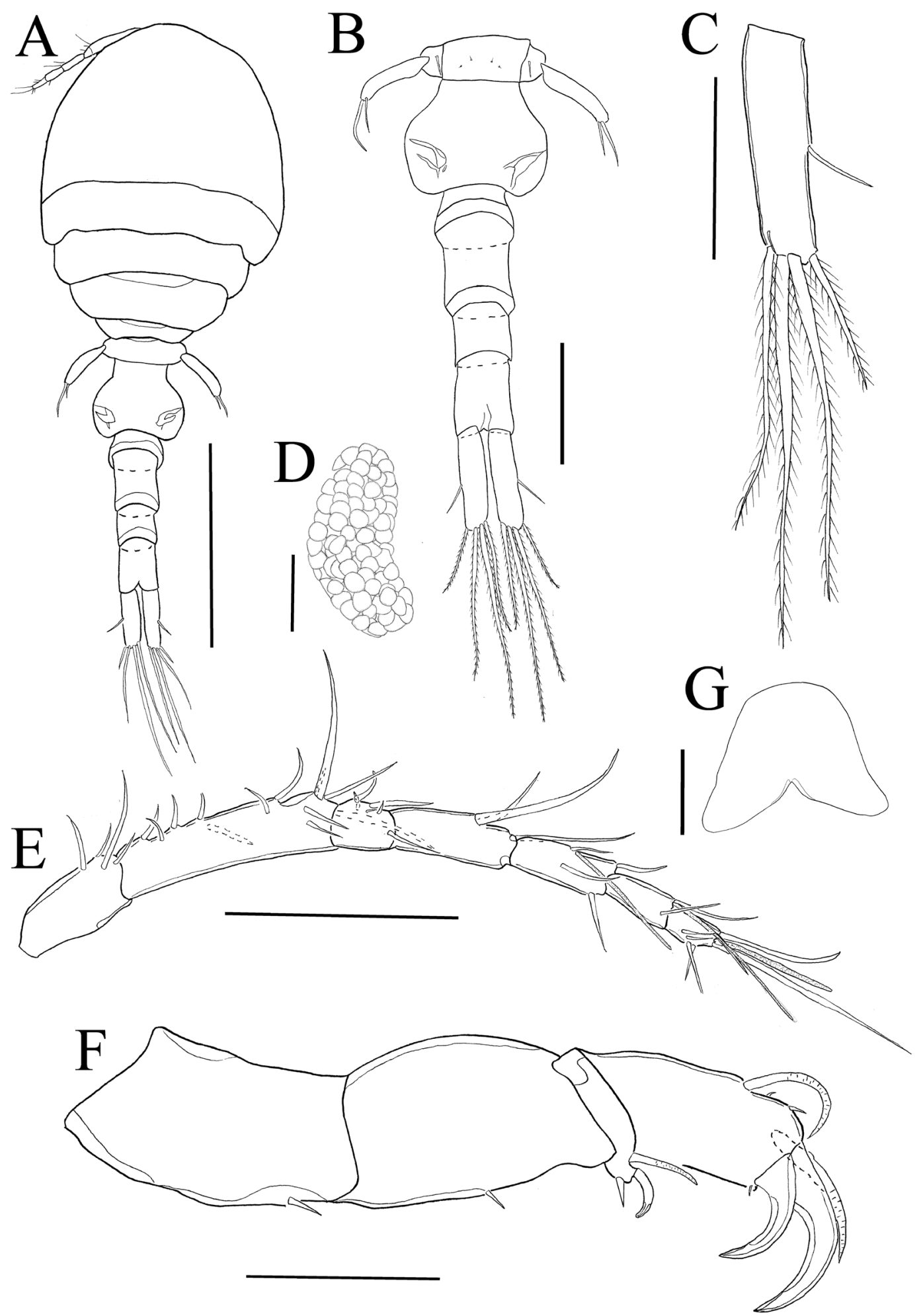

Fig. 1. Doridicola similis, female (NSMT-Cr 25448). A, habitus, dorsal; B, urosome, dorsal; C, caudal ramus, dorsal; D, egg sac; E, antennule; F, antenna; G, labrum. Scale bars: A, $500 \mu \mathrm{m} ; \mathrm{B}, \mathrm{D}, 200 \mu \mathrm{m}$; C, G, $50 \mu \mathrm{m} ; \mathrm{D}, \mathrm{E}, 100 \mu \mathrm{m}$.

Description of female. Body (Fig. 1A) cyclopiform, $1.45-1.65$ (1.54) $\mathrm{mm}$ long (excluding setae on caudal rami) and $0.55-0.63(0.59) \mathrm{mm}$ wide (greatest width of cephalothorax) (measurements based on 5 specimens). Prosome (Fig. 1A) comprising cephalosome and four pedigerous somites. Anterior margin of cephalothorax smoothly rounded. Cephalosome separated by dorsal furrow from first pediger- ous somite, with protrusions at posterolateral corners of latter. First to fourth pedigerous somites progressively decreasing in size. Urosome (Fig. 1B) 5-segmented. Fifth pedigerous somite wider than long. Genital double somite (Figs 1B, $3 C)$ wider than long, respectively 200-250 (235) $\times 190-235$ (210) $\mu \mathrm{m}$, with anterodorsal bulge and posterolateral eggsac attachment areas. Three free abdominal somites (Fig. 

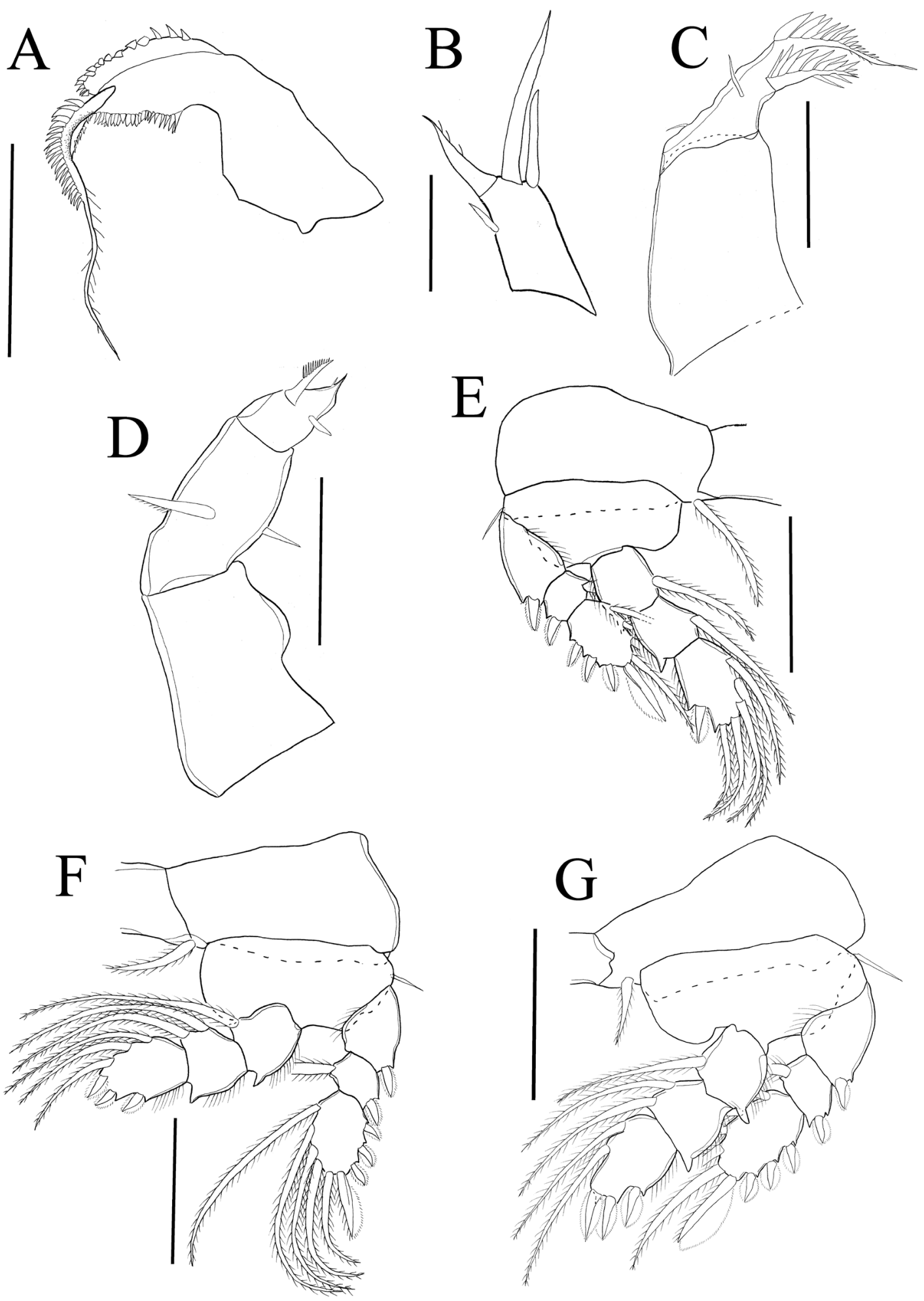

Fig. 2. Doridicola similis, female (NSMT-Cr 25448). A, mandible; B, maxillule; C, maxilla; D, maxilliped; E, leg 1; F, leg 2; G, leg 3. Scale bars: A, C, D, $50 \mu \mathrm{m} ; \mathrm{B}, 10 \mu \mathrm{m} ; \mathrm{E}-\mathrm{G}, 100 \mu \mathrm{m}$.

1B) $85-150(110) \times 105-123(116), 75-103(92) \times 95-105$ (102), and 128-138 (133) $\times 98-113(107) \mu \mathrm{m}$ long and wide, respectively. Caudal rami (Fig. 1C) 3.80-4.12 (4.00) times longer than wide, $165-185(177) \times 40-45(44) \mu \mathrm{m}$, and bearing 4 plumose setae at posterior extremity and 2 additional short setae ( 1 on outer lateral margin and other near posterior extremity). Egg sac (Fig. 1D) elliptical and slightly curved, $540 \times 240 \mu \mathrm{m}(n=1)$

Antennule (Fig. 1E) 7-segmented, with armature formula: $4,13,6,3,4+1$ aesthetasc, $2+1$ aesthetasc, and $7+1$ aesthetasc. Antenna (Fig. 1F) 4-segmented, with armature formula: 1, 1, 2+1 small claw, and 5+2 large, unequal claws. Labrum (Fig. 1G) with pair of large posteroventral lobes. Mandible (Fig. 2A) with shallow proximal notch; inner mar- 
Table 1. Armature formula of legs 1-4 of Doridicola similis Ho and Kim, 2001, adult female, spines and setae indicated in Roman and Arabic numerals, respectively.

\begin{tabular}{lccll}
\hline & Coxa & Basis & \multicolumn{1}{c}{ Exopod } & \multicolumn{1}{c}{ Endopod } \\
\hline Leg 1 & $0-1$ & $1-0$ & I-0; I-1; III, 1, 4 & $0-1 ; 0-1 ;$ I, 5 \\
Leg 2 & $0-1$ & $1-0$ & I-0; I-1; III, I, 5 & $0-1 ; 0-2 ;$ I, II, 3 \\
Leg 3 & $0-1$ & $1-0$ & I-0; I-1; III, I, 5 & $0-1 ; 0-2 ;$ I, II, 2 \\
Leg 4 & $0-1$ & $1-0$ & I-0; I-1; II, 1, 5 & $0-1$; II \\
\hline
\end{tabular}

gin linear with row of short, thick spinules; convex margin with 3 outer scales followed by row of short, thick spinules; terminal lash long, tapering, bilaterally spinulose. Maxillule (Fig. 2B) with 2 terminal and 2 subterminal setae, one of former with spinules. Maxilla (Fig. 2C) 2-segmented; syncoxa unarmed; basis with large seta (seta I) bearing long spinules on both margins, simple seta (seta II) on posterior surface, and simple small seta (seta III) on outer margin of base; terminal lash armed along one side with large spinules. Maxilliped (Fig. 2D) 3-segmented; syncoxa largest, unarmed; basis carrying small simple seta and longer uniserlally spinulate seta; free endopodal segment terminating in barbed spiniform process with long spinulate spine and short simple seta at base.

Legs 1-4 (Figs 2E-G, 3A) biramous with 3-segmented rami, except for 2-segmented endopod of leg 4 . Armature formula of legs 1-4 shown in Table 1.

Leg 5 (Fig. 3B) consisting of elongate free segment with 2 unequal simple setae at tip. Leg 6 (Fig. 3C) represented by 2 small naked setae in posterodorsal area of genital double somite.

Description of male. Body (Fig. 3D) cyclopiform, 1.29-1.49 (1.38) $\mathrm{mm}$ long (excluding setae on caudal rami) and $0.39-0.46(0.42) \mathrm{mm}$ wide (measurements based on 10 specimens). Prosome 5-segmented and urosome 6-segmented. Genital somite wider than long, 235-295 (267) $\times 210-$ $235(227) \mu \mathrm{m}$. Caudal rami 3.25-3.63 (3.41) times longer than wide. Antenna (Fig. 3E) similar to that of female but proximal half of inner margin of second segment ornamented with small spinules.

Maxilliped (Fig. 3F) 4-segmented, subchelate; syncoxa unarmed; basis with row of spinules and 2 inner setae; free endopodal segment smallest, unarmed; terminal claw bearing lamellae near tip and 2 unequal setae near base. Leg 5 (Fig. 3G) tipped with 2 unequal simple setae. Leg 6 (Fig. $3 \mathrm{H}$ ) represented by small lobe bearing 2 ventral naked setae at posterolateral corner of genital somite.

Host. Sepioteuthis sp. 2 (called shiro-ika, see Imai and Aoki 2012) (Cephalopoda: Myopsida: Loliginidae)

Locality. Western North Pacific Ocean, Owase Bay off the coast of Hiki-Motoura, Kihoku, Mie Prefecture, Honshu, central Japan.

Site. Gills

Number of copepods per squid. Forty-one and 91 individuals each on the two squids examined (220 and $205 \mathrm{~mm}$ DML).

Remarks. As indicated by Ho and Kim (2001), the three species of Doridicola reported from cephalopods, viz.,
Doridicola longicauda (Claus, 1860) from Sepia officinalis Linnaeus, 1758 in Europe (Ho 1983), Doridicola similis Ho and Kim, 2001 from Sepioteuthis lessoniana Férussac in Lesson, 1831 in Thailand (Ho and Kim 2001), and D. sepiae from Sepia esculenta in Japan and Korea (Izawa 1976; Kim 1998), are morphologically very similar, but they are distinguished from each other by the length-to-width ratio of the female caudal rami: 2.2, 4.22, and 3.18 times longer than wide, respectively (see also the next paragraph). In the female specimens examined in this study, this value ranges from 3.80 to 4.12 (mean: 4.00) and is almost identical to that in D. similis. Our specimens are also separated from $D$. longicauda and D. sepiae by the absence of a protrusion on the anterior margin of the cephalothorax. It is thus reasonable to identify our specimens as $D$. similis, although the following slight differences are found between Japanese and Thai specimens: (1) scales are present on the convex margin of the mandible in the Japanese female specimens but absent in the Thai females, and (2) a seta on the basis of the leg 4 is naked in the Japanese female specimens but barbed in the Thai females.

Ho and Kim (2001) reported, based on Izawa (1976), that the length-to-width ratio of the female caudal rami of D. sepiae was $3.18: 1$, which, however, differs from the value ("nearly 3.5 times") reported by the latter author (p. 92). One possible explanation for this difference is that Ho and Kim (2001) did not notice Izawa's (1976) printed data, and they measured the caudal ramus using Izawa's fig. 1. We obtained a similar ratio (3.13:1 as the average for the left and right caudal rami) from this figure. Using material of $D$. sepiae from Korea, Kim (1998) reported a ratio of 3.22:1.

In the original description of D. similis, Ho and Kim (2001) misidentified maxillary seta III and seta I as "seta I" and "seta III", respectively, both having been originally defined by Humes and Boxshall (1996: 178, fig. 1). Ho and Kim (2001) also misreported the female's leg 4 (fig. 3A), free segment of leg 5 (fig. 3B), and genital area (fig. 3c) as those of the male in their figure caption.

\section{Discussion}

The present collection of $D$. similis represents the second record of the species and a new country record in Japan, which expands its distribution range from the Gulf of Thailand (Ho and Kim 2001) northeast to the western North Pacific Ocean off central Japan. Although the two locations are distantly separated from each other and belong to the tropical and temperate regions, respectively, the sampling site in Japan is constantly affected by a warm current, the Kuroshio, flowing from the Philippines, which may allow $D$. similis to occur there.

The Japanese stock of squids previously known as Sepioteuthis lessoniana is divided into three species, viz., Sepioteuthis sp. 1 (called aka-ika), Sepioteuthis sp. 2 (shiro-ika), and Sepioteuthis sp. 3 (kua-ika), by external morphological features (including the shape of their egg capsules) and molecular data. Sepioteuthis sp. 2 is widely distributed in coastal 


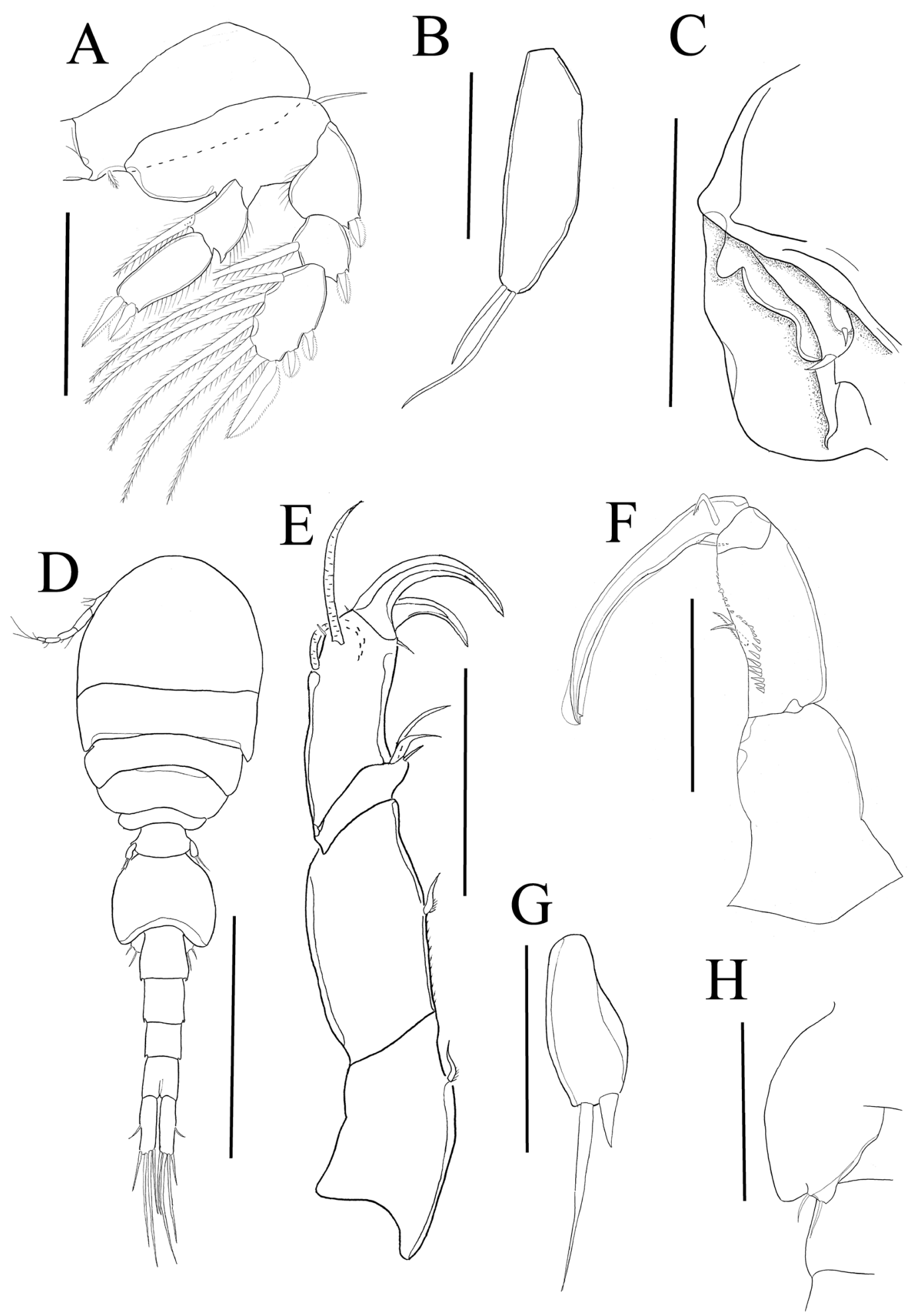

Fig. 3. Doridicola similis. A-C, female (NSMT-Cr 25448): A, leg 4; B, free segment of leg 5; C, posterior surface of genital double-somite and leg 6, dorsal. D-H, male (NSMT-Cr 25449): D, habitus, dorsal; E, antenna; F, maxilliped; G, free segment of leg 5; H, part of genital somite and leg 6, ventral. Scale bars: A-C, $100 \mu \mathrm{m}$; D, $500 \mu \mathrm{m}$; E, F, $100 \mu \mathrm{m} ; \mathrm{G}, 50 \mu \mathrm{m} ; \mathrm{H}, 200 \mu \mathrm{m}$.

waters of the East China Sea, the Sea of Japan, and the western North Pacific Ocean along the Japanese Archipelago from the Ryukyu Islands in the south to southern Hokkaido in the north, while Sepioteuthis sp. 1 and Sepioteuthis sp. 3 occur off the Ryukyu Islands and the Ogasawara Islands (Izuka et al. 1994, 1996; Imai and Aoki 2012; Tomano et al.
2015). In this study, we collected D. similis from Sepioteuthis sp. 2 caught in the Pacific waters of central Japan. It is desirable to study the occurrence of $D$. similis on these closely related host species from different locations in order to document its host utilization and geographical distribution patterns in Japanese waters. 
More than 160 species in 36 families and five orders of cephalopod have been recorded from Japanese waters (Kubodera 1997). Of these species, only five nominal and three unidentified species, namely Sepia esculenta (Sepioidea: Sepiidae), Sepioteuthis sp. 2 (Myopsida: Loliginidae), Graneledone sp., Octopus longispadiceus, Octopus sp. (Octopoda: Octopodidae), Opisthoteuthis californiana (Octopoda: Opisthoteuthidae), Muusoctopus profundorum, and M. fuscus (Octopoda: Enteroctopodidae), have been reported to harbor a total of seven species of symbiotic copepod (Izawa 1976; Avdeev 1982, 1986; this study; see the Introduction herein). Much remains to be studied on the symbiotic copepod fauna of Japanese cephalopods.

\section{Acknowledgments}

We thank Satoshi Tomano and Atsushi Tsuyuki, Graduate School of Biosphere Science, Hiroshima University, for providing the gill samples of Sepioteuthis sp. for our study. We are also grateful to two anonymous reviewers and Mark J. Grygier, Lake Biwa Museum, for valuable comments to improve the manuscript.

\section{References}

Avdeev, G. V. 1982. New harpacticoid copepod parasites of octopods in the north-west Pacific. Parazitologia 16: 107-116. [In Russian with English abstract]

Avdeev, G. V. 1986. New harpacticoid copepods associated with Pacific cephalopods. Crustaceana 51: 49-65.

Ho, J.-S. 1980. Origin and dispersal of Mytilus edulis in Japan deduced from its present status of copepod parasitism. Publications of the Seto Marine Biological Laboratory 25: 293-313.

Ho, J.-S. 1983. Metaxymolgus longicauda (Claus), a copepod associated with the cuttlefish, Sepia officinalis L. Journal of the Marine Biological Association of the United Kingdom 63: 199-203.

Ho, J.-S. and Kim, I.-H. 2001. New species of Doridicola (Copepoda, Rhynchomolgidae) from Thailand, with a cladistic analysis of the genus. Journal of Crustacean Biology 21: 78-89.
Humes, A. G. and Boxshall, G. A. 1996. A revision of the lichomolgoid complex (Copepoda: Poecilostomatoida), with the recognition of six new families. Journal of Natural History 30: 175-227.

Humes, A. G. and Gooding, R. U. 1964. A method for studying the external anatomy of copepods. Crustaceana 6: 238-240.

Humes, A. G. and Stock, J. H. 1983. Redefinition of the genus Doridicola Leydig, 1853, synonymy of Metaxymolgus Humes \& Stock, 1972, and establishment of a new genus, Critomolgus (Copepoda, Poecilostomatoida, Lichomolgidae). Bulletin Zoölogisch Museum, Universiteit van Amsterdam 9: 93-98.

Imai, H. and Aoki, M. 2012. Genetic diversity and genetic heterogeneity of bigfin reef squid "Sepioteuthis lessoniana" species complex in northwestern Pacific Ocean. Pp. 151-160. In: Calskan, M. (Ed.) Analysis of Genetic Variation in Animals. InTech, Rijeka, Croatia.

Izawa, K. 1976. Two semi-parasitic copepods of marine invertebrates from Japan (Cyclopoida: Lichomolgidae). Publications of the Seto Marine Biological Laboratory 23: 89-98.

Izawa, K. 1986. On the development of parasitic Copepoda. IV. Ten species of poecilostome cyclopoids, belonging to Taeniacanthidae, Tegobomolochidae, Lichomolgidae, Philoblennidae, Myicolidae, and Chondracanthidae. Publications of the Seto Marine Biological Laboratory 31: 81-162.

Izuka, T., Segawa, S., Okutani, T., and Numachi, K. 1994. Evidence on the existence of three species in the oval squid Sepioteuthis lessoniana complex in Ishigaki Island, Okinawa, southwestern Japan, by isozyme analyses. Venus 53:217-228.

Izuka, T., Segawa, S., and Okutani, T. 1996. Biochemical study of the population heterogeneity and distribution of the oval squid Sepioteuthis lessoniana complex in southwestern Japan. American Malacological Bulletin 12: 129-135.

Kim, I.-H. 1998. Illustrated Encyclopedia of Fauna and Flora of Korea. Vol. 38. Cirripedia, Symbiotic Copepoda, Pycnogonida. Ministry of Education, Seoul. 1038 pp. [In Korean]

Kubodera, T. 1997. Cephalopoda. Pp. 106-107. In: Okutani, T., Takeda, M., and Imafuku, M. (Eds) The Encyclopedia of Animals in Japan. Vol. 7. Invertebrates. Heibonsha, Tokyo. [In Japanese]

Nagasawa, K. 1993. Review of human pathogenic parasites in the Japanese common squid (Todarodes pacificus). Pp. 293-312. In: Okutani, T., O'Dor, R. K., and Kubodera, T. (Eds) Advances in Cephalopod Fisheries Biology. Tokai University Press, Tokyo.

Tomano, S., Sanchez, G., Ueno, K., Ueta, Y., Ohara, K., and Umino, T. 2015. Microsatellite DNA variation of oval squid Sepioteuthis sp. 2 reveals a single fishery stock on the coastline of mainland Japan. Fisheries Science 81: 839-847. 